\title{
Bisphosphonate-associated osteonecrosis of the jaw
}

\author{
Aliya Khan MD FRCPC FACP FACE
}

工 n 2003, the first reports describing osteonecrosis of the jaw in patients receiving bisphosphonates were published. ${ }^{1}$ About $95 \%$ of these cases occurred among cancer patients receiving high-dose intravenous bisphosphonates. Approximately 5\% of the reported cases have been in osteoporosis patients receiving lowdose bisphosphonate therapy. ${ }^{2}$

The Canadian Task Force on Osteonecrosis of the Jaw, with representatives from medical, surgical, and pathology disciplines, has developed Canadian consensus practice guidelines for bisphosphonate-associated osteonecrosis of the jaw. ${ }^{3}$ These guidelines are based on a systematic review of the literature.

Osteonecrosis of the jaw is an uncommon condition with many recognized causes. Traditionally, it has been associated with head and neck irradiation. It can also occur in the presence of periodontal disease, local malignancy, chemotherapy, glucocorticoid therapy, or trauma. ${ }^{1-6}$ Recently, however, high-dose intravenous bisphosphonates have been identified as a risk factor for osteonecrosis of the jaw among oncology patients. Lowdose bisphosphonate use in patients with osteoporosis or other metabolic bone disease has not been causally linked to the development of osteonecrosis of the jaw.

Bisphosphonates have been widely used in the management of osteoporosis and metabolic bone disease. They have proven to be effective in reducing the risk of fracture and have recently been shown to improve mortality. ${ }^{7}$ They are valuable in the management of skeletal complications of malignancy, namely metastatic bone disease and hypercalcemia of malignancy, and are a key treatment option for cancer patients with metastatic disease..$^{8-14}$

The mechanism by which bisphosphonates might contribute to the development of osteonecrosis of the jaw is not well understood. Osteonecrosis of the jaw can occur in patients who are not taking bisphosphonates and in patients without traditional risk factors.

\section{Diagnosis}

If exposed bone is present in the maxillofacial region for more than 8 weeks in the absence of radiotherapy to the jaw in a patient who has been on bisphosphonate therapy, the diagnosis can be confirmed clinically. It is important to exclude other conditions that can present similarly. These include local malignancy, trauma, periodontal disease, and lingual mandibular sequestration and ulceration. ${ }^{15}$ Lingual mandibular sequestration and ulceration is a spontaneous sequestration that was described before the availability of amino bisphosphonates. It is a self-limiting process that spontaneously heals within 3 days to 12 weeks. ${ }^{16}$

\section{Incidence}

Among cancer patients receiving high-dose intravenous bisphosphonates, osteonecrosis of the jaw is dependent on dose and duration of therapy, ${ }^{17-20}$ and has an estimated incidence of $1 \%$ to $12 \% .{ }^{17,21-24}$ Among osteoporosis patients, bisphosphonate-associated osteonecrosis of the jaw is rare and the incidence might not be greater than the natural background incidence of the condition. Postmarketing data and observational studies indicate an estimated incidence of less than 1 case per 100000 person-years of exposure to oral amino bisphosphonates. ${ }^{25}$

\section{Prevention and treatment}

All patients receiving bisphosphonate therapy should ensure that they maintain good oral hygiene and follow the Canadian Dental Association recommendations of semiannual visits to their dentists. ${ }^{26}$ Quitting smoking and limiting alcohol intake should be encouraged. Before starting intravenous bisphosphonate therapy for a cancer patient, a detailed examination and panoramic x-ray scans of the oral cavity should be completed. If an invasive procedure is necessary while on high-dose intravenous bisphosphonate therapy, the bisphosphonate treatment should be interrupted, if medically possible, and any essential dental work should be completed (Figure $\mathbf{1}^{26}$ ). Ideally, bisphosphonate therapy should be stopped during the healing period. ${ }^{27,28}$

For osteoporosis patients requiring urgent oral surgery, interruption of bisphosphonate therapy is recommended during the healing period. If surgery is not urgent, then bisphosphonate treatment can be discontinued for several months before the planned procedure and restarted when healing is complete. ${ }^{29,30}$

Treatment of osteonecrosis of the jaw currently focuses on addressing local pain, treating secondary infection, and ensuring adequate nutritional intake and appropriate dietary supplementation (using a feeding tube, if necessary). It is recommended that surgery be limited to removing necrotic debris. ${ }^{31}$

\section{Conclusion}

Bisphosphonate-associated osteonecrosis of the jaw is an important condition seen most commonly in oncology patients receiving high-dose intravenous 
Figure 1. Bisphosphonate-associated osteonecrosis of the jaw following a palliative resection of the mandible with insertion of a reconstruction plate: Progressive tissue necrosis has resulted in continued exposure of the bone and reconstruction plate, despite attempts to keep the wound clean.

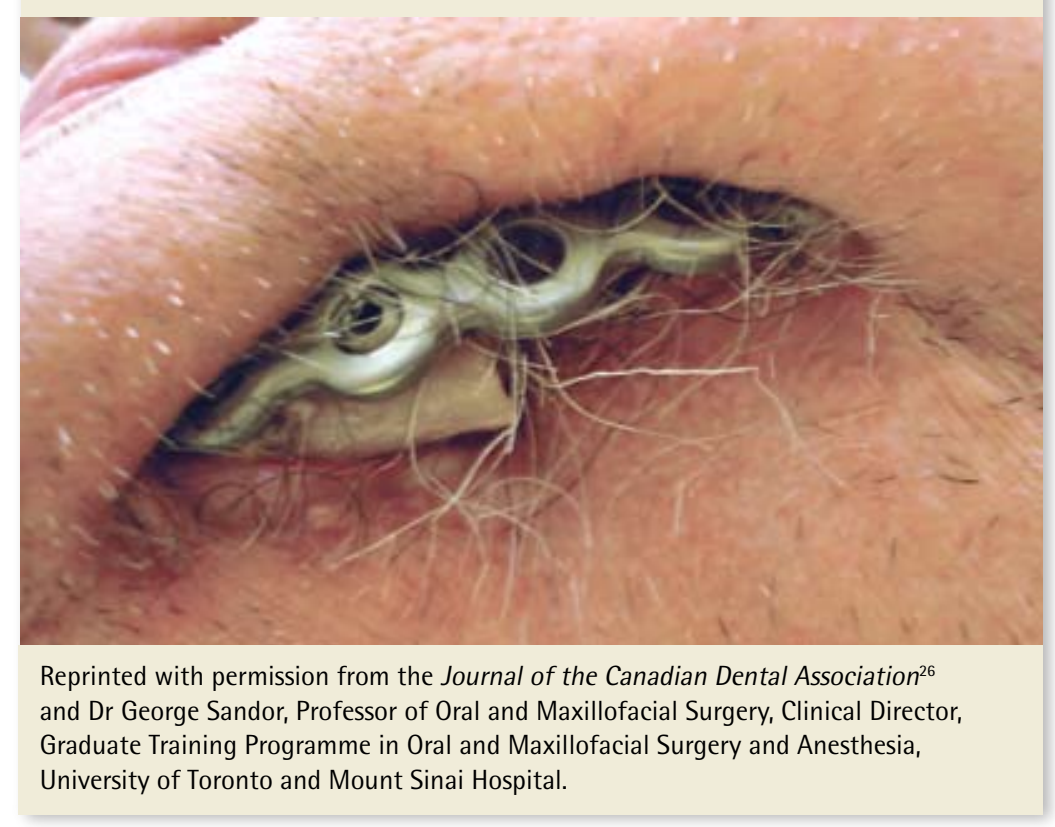

Alan J. Neville, Reena M. Talwar, Cameron M. Clokie, Majd Al Mardini, Terri Paul, Sundeep Khosla, Robert G. Josse, Susan Sutherland, David K. Lam, Robert P. Carmichael, Nick Blanas, David Kendler, Steven Petak, Louis Georges Ste-Marie, Jacques Brown, A. Wayne Evans, Lorena Rios, Brian Lentle, and Juliet E. Compston. The consensus practice guidelines have been endorsed by the following national and international societies: the Canadian Association of Oral and Maxillofacial Surgeons, the Canadian Society of Endocrinology and Metabolism, the Ontario Society of Oral and Maxillofacial Surgeons, the Canadian Academy of Oral and Maxillofacial Pathology and Oral Medicine, the American Association of Clinical Endocrinologists, the International Bone and Mineral Society, and the International Society of Clinical Densitometry.

\section{Competing interests}

Dr Khan is a consultant for Amgen, Novartis, Merck, Lilly, Procter \& Gamble, and Servier, and has received research support from Merck, Novartis, and Procter \& Gamble.

bisphosphonates. Low-dose bisphosphonates given either orally or intravenously in osteoporosis patients have not been causally linked to the development of osteonecrosis of the jaw. A temporal relationship between high-dose intravenous bisphosphonates and osteonecrosis of the jaw exists in cancer patients.

As the condition can occur spontaneously in the absence of known risk factors and the background incidence is not known, it is important to ensure that all patients maintain good dental hygiene and see their dentists semiannually. Prospective data will provide a greater understanding of the pathogenesis and the true incidence of osteonecrosis of the jaw occurring in association with bisphosphonates, as well as the background incidence of spontaneous osteonecrosis of the jaw.

Dr Khan is a Professor of Clinical Medicine at McMaster University in Hamilton, Ont, and Chair of the Canadian Task Force on Osteonecrosis of the Jaw.

\section{Acknowledgment}

The development of the Canadian guidelines on osteonecrosis of the jaw was funded by the Canadian Association of Oral and Maxillofacial Surgeons' Foundation for Continuing Education and Research. The Canadian Task Force on Osteonecrosis of the Jaw comprises the following members: Aliya A. Khan, George K.B. Sandor, Edward Dore, Archibald D. Morrison, Mazen Alsahli, Faizan Amin, Edmund Peters, David A. Hanley, Sultan R. Chaudry, David W. Dempster, Francis H. Glorieux,
Correspondence to: Dr Aliya Khan, 209-331 Sheddon Ave, Oakville, ON L6J 1X8; e-mail avkhan@aol.com

1. Marx RE. Pamidronate (Aredia) and zoledronate (Zometa) induced avascular necrosis of the jaws: a growing epidemic. J Oral Maxillofac Surg 2003;61(9):1115-7.

2. Favus MJ. Diabetes and the risk of osteonecrosis of the jaw [editorial]. J Clin Endocrinol Metab 2007;92(3):817-8

3. Khan AA, Sándor GKB, Dore E, Morrison AD, Alsahli M, Amin F, et al. Canadian consensus practice guidelines for bisphosphonate associated osteonecrosis of the jaw. J Rheumatol 2008 Jun 1. Epub ahead of print. Available from: http://jrheum.com/earlyrelease.html. Accessed 2008 May 30

4. Advisory Task Force on Bisphosphonate-Related Osteonecrosis of the Jaws, American Association of Oral and Maxillofacial Surgeons. American Association of Oral and Maxillofacial Surgeons position paper on bisphosphonate-related osteonecrosis of the jaws. J Oral Maxillofac Surg 2007;65(3):369-76.

5. Ruggiero SL, Mehrotra B, Rosenberg TJ, Engroff SL. Osteonecrosis of the jaws associated with the use of bisphosphonates: a review of 63 cases. J Oral Maxillofac Surg 2004;62(5):527-34

6. Kademani D, Koka S, Lacy MQ, Rajkumar SV. Primary surgical therapy for osteonecrosis of the jaw secondary to bisphosphonate therapy. Mayo Clin Proc 2006;81(8):1100-3

7. Lyles KW, Colón-Emeric CS, Magaziner JS, Adachi JD, Pieper CF, Mautalen C, et al. Zoledronic acid in reducing clinical fracture and mortality after hip fracture N Eng J Med 2007; 1 (11):nihpa40967.

8. Brown JP, Josse RG. Scientific Advisory Council of the Osteoporosis Society of Canada: 2002 clinical practice guidelines for the diagnosis and management of osteoporosis in Canada. CMAJ 2002;167(10 Suppl):S1-34.

9. Berenson JR, Hillner BE, Kyle RA, Anderson K, Lipton A, Yee GC, et al. American Society of Clinical Oncology clinical practice guidelines: the role of bisphosphonates in multiple myeloma. J Clin Oncol 2002;20(17):3719-36.

10. Berry S, Waldron T, Winquist E, Lukka H. The use of bisphosphonates in men with hormone-refractory prostate cancer. Practice guideline report No. 3-14. Toronto, ON: Cancer Care Ontario; 2005. Available from: www.cancercare. on.ca/pdf/pebc3-14s.pdf. Accessed 2008 May 30.

11. Berry S, Waldron T, Winquist E, Lukka $\mathrm{H}$. The use of bisphosphonates in men with hormone-refractory prostate cancer: a systematic review of randomized trials. Can J Urol 2006;13(4):3180-8.

\section{References}


12. Hillner BE, Ingle JN, Chlebowski R, Gralow J, Yee JC, Janjan NA, et al. American Society of Clinical Oncology 2003 update on the role of bisphosphonates and bone health issues in women with breast cancer. J Clin Oncol 2003;21(21):4042-57.

13. Kyle RA, Yee GC, Somerfield MR, Flynn PJ, Halabi S, Jagannath S, et al. American Society of Clinical Oncology 2007 clinical practice guideline update on the role of bisphosphonates in multiple myeloma. J Clin Oncol 2007:25(17):2464-72.

14. Saad F, Gleason DM, Murray R, Tchekmedyian S, Venner P, Lacombe L, et al. A randomized, placebo-controlled trial of zoledronic acid in patients with hormone-refractory metastatic prostate carcinoma. J Natl Cancer Inst 2002;94(19): 1458-68.

15. Khosla S, Burr D, Cauley J, Dempster DW, Ebeling PR, Felsenberg D, et al. Bisphosphonate-associated osteonecrosis of the jaw: report of a task force of the American Society for Bone and Mineral Research.J Bone Miner Res 2007;22(10):1479-91.

16. Peters E, Lovas GL, Wysocki GP. Lingual mandibular sequestration and ulceration. Oral Surg Oral Med Oral Pathol 1993;75(6):739-43.

17. Bamias A, Kastritis E, Bamia C, Moulopoulos LA, Melakopoulos I, Bozas G, et al. Osteonecrosis of the jaw in cancer after treatment with bisphosphonates: incidence and risk factors. J Clin Oncol 2005;23(34):8580-7.

18. Marx RE, Sawatari Y, Fortin M, Broumand V. Bisphosphonate-induced exposed bone (osteonecrosis/osteopetrosis) of the jaws: risk factors, recognition, prevention, and treatment. J Oral Maxillofac Surg 2005;63(11):1567-75.

19. Mavrokokki T, Cheng A, Stein B, Goss A. Nature and frequency of bisphosphonate-associated osteonecrosis of the jaws in Australia. J Oral Maxillofac Surg 2007;65(3):415-23

20. Dimitrakopoulos I, Magopoulos C, Karakasis D. Bisphosphonate-induced avascular osteonecrosis of the jaws: a clinical report of 11 cases. Int J Oral Maxillofac Surg 2006;35(7):588-93

21. Cafro AM, Barbarano LA, Andriani A. Osteonecrosis of the jaw associated with chronic bisphosphonates therapy: an Italian experience [abstract]. Blood 2005;106(11):5152a

22. Dimopoulos MA, Kastritis E, Anagnostopoulos A, Melakopoulos I, Gika D, Moulopoulos LA, et al. Osteonecrosis of the jaw in patients with multiple myeloma treated with bisphosphonates: evidence of increased risk after treatment with zoledronic acid. Haematologica 2006;91(7):968-71.

23. Durie BG, Katz M, Crowley J. Osteonecrosis of the jaws and bisphosphonates. N Engl J Med 2005;353(1):99-102

24. Tosi P, Zamagni E, Cangini D, Tacchetti P, Offidani M, Ronconi S, et al Bisphosphonates and osteonecrosis of the jaws: incidence in a homogeneous series of patients with newly diagnosed multiple myeloma treated with zoledronic acid [abstract]. Blood 2005;106(11):3461a.

25. Felsenberg D, Hoffmeister B, Amiling M. Bisphosphonattherapie assoziierte. Kiefernekrosen Deutsches Arzteblatt. In press.

26. Lam DK, Sándor GK, Holmes HI, Evans AW, Clokie CM. A review of bisphosphonate-associated osteonecrosis of the jaws and its management. J Can Dent Assoc 2007;73(5):417-22.

27. Kyle RA, Yee GC, Somerfield MR, Flynn PJ, Halabi S, Jagannath S, et al. American Society of Clinical Oncology 2007 clinical practice guideline update on the role of bisphosphonates in multiple myeloma. J Clin Oncol 2007;25(17):2464-72.

28. Zavras AI, Zhu S. Bisphosphonates are associated with increased risk for jaw surgery in medical claims data: is it osteonecrosis? J Oral Maxillofac Surg 2006;64(6):917-23.

29. Melo M, Obeid G. Osteonecrosis of the jaws in patients with a history of receiving bisphosphonate therapy. Strategies for prevention and early recognition. J Am Dent Assoc 2005;136(12):1675-81.

30. Ruggiero S, Gralow J, Marx RE, Hoff AO, Schubert MM, Huryn JM, et al. Practical guidelines for the prevention, diagnosis, and treatment of osteonecrosis of the jaw in patients with cancer. J Oncol Pract 2006;2(1):7-14

31. Farah CS, Savage NW. Oral ulceration with bone sequestration. Aust Dent 2003;48(1):61-4

\section{Punch biopsy \\ Minor surgery video series}

\author{
Charles Czarnowski MD CCFP \\ David Ponka MDCM CCFP(EM) \\ Ravi Rughani MD CCFP \\ Paul Geoffrion MD CCFP
}

$\mathrm{T}$

his month, check out the latest minor surgery video-"Punch Biopsy"-from the Élisabeth Bruyère Family Medicine Centre in Ottawa, Ont. The video reviews the equipment, technique, and postoperative care required for this procedure.

The video "Punch Biopsy" is available at www.cfp.ca. Go to this article on-line, then click on CFPlus in the menu at the top right-hand side of the page.

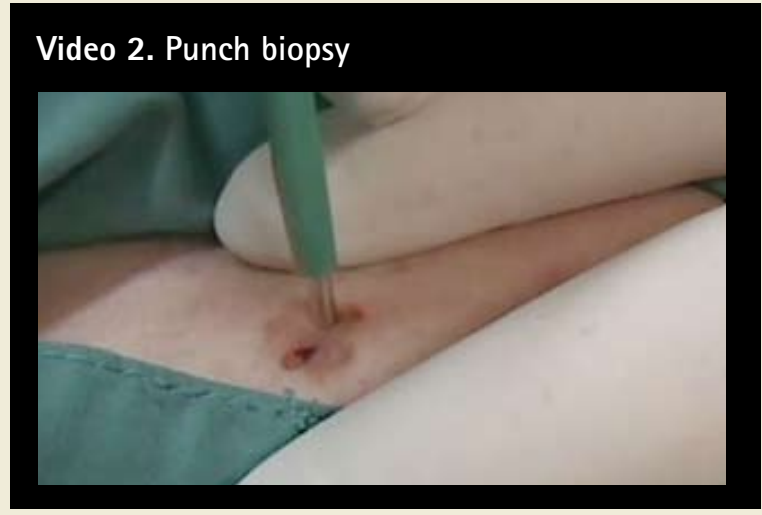

Past minor surgery procedure videos can be accessed on-line at www.cfp.ca. On the homepage, click on Collections in the left-hand menu, then click on Video Series.

\section{Competing interests}

None declared

\section{Drs Czarnowski and Ponka are Assistant} Professors in the Department of Family Medicine at the University of Ottawa in Ontario. Dr Rughani is a family practitioner at the Geraldton District Hospital in Geraldton, Ont. Dr Geoffrion is a family practitioner in Calgary, Alta.

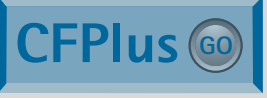

The video "Punch Biopsy" is available at www.cfp.ca. Go to the full text of this article on-line, then click on CFPlus in the menu at the top right-hand side of the page. 